\title{
Exposure monitoring and controlling hazards in additive manufacturing processes
}

Tyler John Kusich

Follow this and additional works at: https://researchrepository.wvu.edu/etd

\section{Recommended Citation}

Kusich, Tyler John, "Exposure monitoring and controlling hazards in additive manufacturing processes" (2017). Graduate Theses, Dissertations, and Problem Reports. 4007.

https://researchrepository.wvu.edu/etd/4007

This Problem/Project Report is protected by copyright and/or related rights. It has been brought to you by the The Research Repository @WVU with permission from the rights-holder(s). You are free to use this Problem/Project Report in any way that is permitted by the copyright and related rights legislation that applies to your use. For other uses you must obtain permission from the rights-holder(s) directly, unless additional rights are indicated by a Creative Commons license in the record and/ or on the work itself. This Problem/Project Report has been accepted for inclusion in WVU Graduate Theses, Dissertations, and Problem Reports collection by an authorized administrator of The Research Repository @ WVU. For more information, please contact researchrepository@mail.wvu.edu. 


\title{
Exposure monitoring and controlling hazards in additive manufacturing processes
}

\author{
Tyler J. Kusich
}

Problem Report submitted to the College of Engineering and Mineral Resources at West Virginia University

in partial fulfillment of the requirements for the degree of

Masters of Science in

Industrial Hygiene

\author{
Approved by \\ Steven E. Guffey, Ph.D., CIH, Chair \\ Xinjian He, Ph.D. \\ Mike McGarvey, M.S.
}

Department of Industrial and Management Systems Engineering

\author{
Morgantown, West Virginia \\ 2017
}

Keywords: Industrial Hygiene, Exposure Monitoring, Metal Powders, Additive Manufacturing.

Copyright 2017 Tyler Kusich 


\section{Abstract \\ Exposure monitoring and controlling hazards in additive manufacturing processes \\ Tyler John Kusich}

Additive manufacturing (AM) is a relatively new field that promises advancement in various disciplines such as medical, aerospace, and consumer products. One of the recent developments in additive manufacturing is with the use of metal powders, such as aluminum, nickel, and chromium. AM processes are projected to become more common as the technology advances and the applications spread into a variety of different industries. There are several health and safety risks that have been identified with the use of these powders, including combustible dust and health exposure issues. This study was aimed at looking at some of the issues with these risks, and to give baseline exposure monitoring for several common processes in additive manufacturing.

Exposure monitoring was performed for two lab scale operations, two metal printing operations, and a powder creation operation. Samples were either analyzed for chrome and nickel, or hexavalent chrome. Results of the 17 exposure monitoring samples showed various levels of exposures. Excluding the one outlier sample, 4 of the 17 samples taken were over the occupational exposure limit during the sample duration. Due to the short duration of these tasks, none of the results are over the full shift occupational exposure limit for their respective elements.

In conclusion, these results suggest that the current operations do not pose a risk for exposure above the occupational exposure limits. These results also suggest that changes in the process, for example a scale-up of powder used or a change in the alloy composition, could lead to overexposures to employees. 


\section{Acknowledgements}

I would like to first express my gratitude to Dr. Steven Guffey, the chair of my committee and advisor. Without his invaluable recommendations and support, this problem report would not have been possible. I feel grateful to have learned from him throughout my master's program studies. I would also like to express my gratitude to committee member Dr. Xinjian He, for graciously lending his time and knowledge to this problem report.

I would like to also express my appreciation to Jennifer Kapp and Mike McGarvey, who have both mentored and worked alongside me throughout my few years as an industrial hygienist. Without their wonderful support and knowledge, I would not be where I am today.

Finally, I would like to express my gratitude to Stephanie Chan, my fiancée. Her support and optimism gave me the confidence and motivation to keep pursuing my work. 


\section{Table of Contents}

\section{Contents}

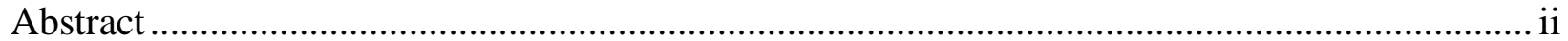

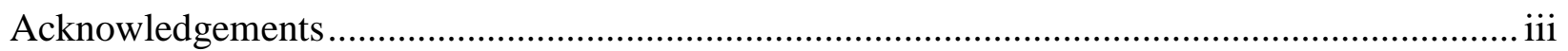

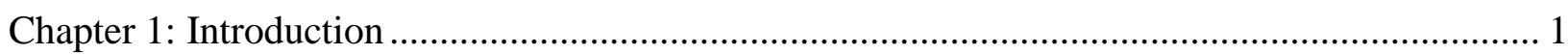

Particle Dynamics and Safety Issues with Additive Manufacturing Metal Powders................ 2

Health Hazards Associated with Common Additive Manufacturing Metal Powders................ 5

Additional EHS Risks in Additive Manufacturing .......................................................... 9

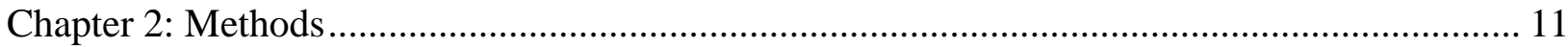

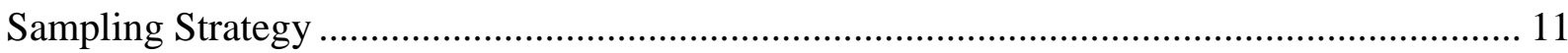

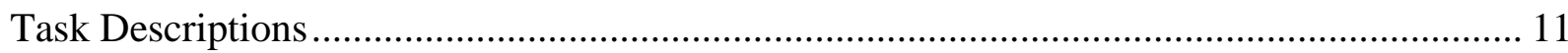

Binder-Jet AM printer operation wand cleanout with nickel powder ............................. 11

Laser AM printer operation machine cleanout ............................................................ 12

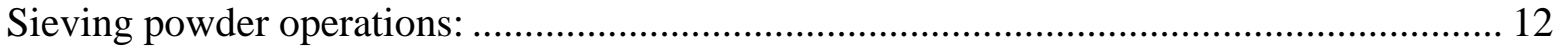

Sample Preparation - Homogenizing bottles of powder.................................................. 12

Nickel atomization cleanout and maintenance ............................................................. 13

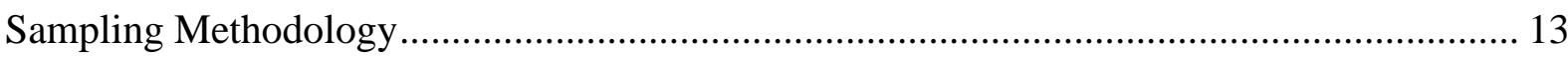

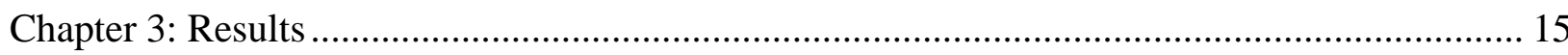

Exposure Monitoring Results and Statistics............................................................. 15

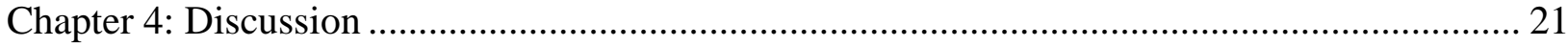

Controlling for AM Hazards and Hierarchy of Controls .................................................. 21

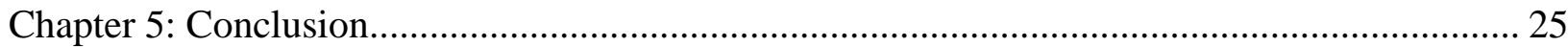

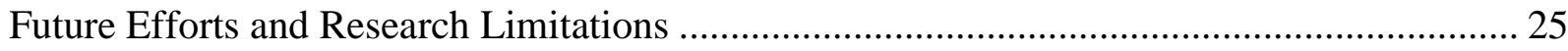

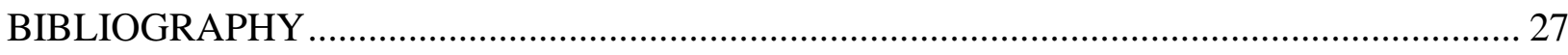

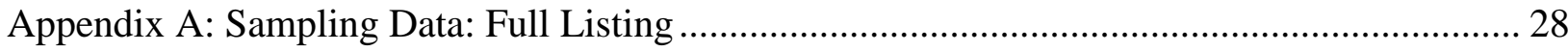

Appendix B: Sampling Data - Employee Name, Time, and Date.......................................... 29 


\section{List of Tables}

Table 1.1 - Inconel 625 Chemical composition, by $\%$

Table 1.2 - Inconel 718 Chemical composition, by \%

Table 1.3 - List of Occupational Exposure Limits of materials in Nickel Alloys

Table 2.1 - Sampling Analyte Parameters

Table 3.1 - Samples taken per task.

Table 3.2 - Exposure limits per analyte

Table 3.3 - Sampling data for AM printing operations

Table 3.4 - Sampling data for Lab Scale operations

Table 3.5 - Sampling data for Nickel Atomizer Cleanout

Table 3.6 - Nickel exposure data confidence interval

\section{List of Figures}

Figure 1.1 - Explosion Pentagon for Combustible Dust

Figure 2.1 - Cassette placement on PAPR. 


\section{Chapter 1: Introduction}

Additive manufacturing (AM) is the creation of parts "additively". Instead of traditional manufacturing processes where parts are created by removing material from a larger piece of material, or by casting and forging processes, products in additive manufacturing are created by adding parts together. These processes, also called "3D printing”, add successive layers of material on top of each other to eventually create an object.

Traditionally, additive manufacturing operations use a process called "fused deposition modeling”, which deposits material from a plastic coil. These are typically polymers, such as Acrylonitrile Butadiene Styrene and Polylactic acid. These polymers are then layered on top of each other successively to create a part. Some polymer compounds do present health hazards and could be a focus of further study with future advancements of AM processes (Lithner, 2011). This study will focus on operations that utilize metal powder, which have substantial toxicity and risk from combustion of the powder.

Additive manufacturing has several advantages. The printing process allows for additional complexity in part design due to the layer by layer formation. The process uses metal more efficiently, allowing less material to be needed per part compared to traditional manufacturing processes. If the part design must be changed, it can be done by changing a CAD file, not the whole process. Because of this, there is very little lead time needed to create a custom part. There are downsides to this process as well. Notably the slow build rate of product, high production costs, knowledge needed for setting design parameters, and limited build size. These processes, while still in their infancy, are considered to have great potential in many fields, including aerospace, automotive, medical and robotics (Staff, 2015). Additive manufacturing has exploded in popularity over the last several years due to the way these advantages can be leveraged in certain products/fields. Many facilities are researching these properties and scaling up additive manufacturing processes.

Metal powders are becoming more common in additive processes, with the technology first appearing in the literature in the 1990s (Amon et al., 1998). As the processes become more common and technology continues to advance, the associated risks will continue to proliferate. To create the powder, a process called atomization is used. A molten metal stream is forced 
through a nozzle at a significant pressure. A gas, typically argon, is passed through the metal stream, causing the molten metal to scatter into small particles, solidifying into powder form. There are variations on this process, such as using a liquid instead of an inert gas, or using centrifugal force, but the concept is similar (Stanislav et al, 2004).

The next step in the process can include sieving to make the particle size more uniform, spheroidizing to ensure all the particles are the same shape and to optimize the geometry for printing, or analytical tests to review the composition. In their final form these powders can be used in $3 \mathrm{D}$ printing processes to make a variety of parts. This can range from lab scale production to full scale production.

In traditional printing operations, metal printing processes are typically conducted in an enclosed chamber, sometimes backfilled with an inert gas such as Argon. This means that the highest exposures will come during maintenance type activities or activities that occur outside of the printing process. After a part is created in a printer, the build chamber must be cleaned out to prepare to create the next part. This involves several steps, such as removing the part and post processing, removing "spent" or impure powder from the chamber, and adding new powder to the chamber.

\section{Particle Dynamics and Safety Issues with Additive Manufacturing Metal Powders}

When working with metals, exposure concerns traditionally came from the processing of metal products in ingot form, such as welding. When working with metal powders, exposure concerns are greater due to the inhalable nature of the material. Due to the small particle sizes of these metal powders, the exposure and safety concerns can differ considerably. The size of a particle is typically measured in micrometers $(\mu \mathrm{m})$. The particle size of these materials can vary depending on the number of factors. The average particle size is typically represented by the $\mathrm{d}_{50 \%}$ - the median particle diameter size. The ideal $\mathrm{d}_{50 \%}$ can vary depending on the process, but typically is within the $10-100 \mu \mathrm{m}$ range. A significant portion of powders are below $10 \mu \mathrm{m}$.

The human respiratory tract mostly filters out large particle sizes $(>100 \mu \mathrm{m})$. However, many of the additive powders fall within the inhalable range $(<100 \mu \mathrm{m})$ and can be breathed into the nose or mouth. Some of these particles fall into the thoracic range $(<10 \mu \mathrm{m})$, the fraction of particles that can enter the airways of the lungs. In addition, a small percentage can be found in 
the respirable particle fraction $(<5 \mu \mathrm{m})$, the portion of inhaled airborne particles that can penetrate beyond the bronchioles to the gas exchange areas of the lungs (Hazard). This can contribute to the health effects of these particles.

In addition, there are some sub-micron particles present during powder operations. A very small percentage is included in the typical powder feedstock, but most of this powder is due to the formation of condensate - powder that has been formed from the vaporization and solidification of molten metal. These particles can penetrate the respiratory air ways easier and more efficiently than larger size particles (Sarofim 2002). The particles also provide additional combustibility risks due to the additional surface area these particles provide.

According to Stoke's law several factors determine the particle settings of these powders, leading to a variety of potential results. Essentially, as the particle diameter and particle density goes up, the rate of particle settling increases as well. This means that the smaller the size of the particle, the greater the inhalation hazard, as the particle is more readily airborne. These small particles also present a greater combustible dust hazard, due to the dust cloud lingering for a longer period and the high surface area of very fine particles. The settling velocity can be computed from Equation 1:

$$
V_{t}=\frac{g d^{2}\left(\rho_{p}-\rho_{m}\right)}{18 \mu}
$$

Where: $\mathrm{Vt}=$ settling velocity

$$
\begin{aligned}
\mathrm{g} & =\text { gravitational constant } \\
\mathrm{d} & =\text { particle diameter } \\
\rho_{\mathrm{p}} & =\text { particle density } \\
\rho_{\mathrm{m}} & =\text { continuous phase density } \\
\mu & =\text { continuous phase viscosity }
\end{aligned}
$$

While this study focuses on the health exposure effects of AM powders, the combustible dust hazards these powders produce cannot be over stated. Elements used in the alloyed AM powders include aluminum, titanium and magnesium, which are combustible in divided powder form. When the particle size gets below a certain threshold, the material becomes combustible, 
typically above the $100 \mu \mathrm{m}$ range (OSHA, 2007).

Combustible dusts are fine materials that can catch fire and explode in air. Metal alloys are combinations of various elements, typically from 3-8 elements per alloy mixture in varying percent contributions. Alloying a metal changes the properties of the material, including the combustibility/explosivity and other particle dynamics. When testing, or using alloyed material, assumptions should be made that the material is combustible or explosive. If sufficient combustibility data is available or testing is performed, then the material can be treated as noncombustible if appropriate. This proves difficult as the publicly available data is limited. For newly created and alloys of obscure composition there is often no data available. Performing combustibility testing is comprehensive, but is often too costly and inefficient when having to test multiple powders. The most efficient route is often to control the metal powder as if it were a highly explosive and combustible material.

Controlling for combustible dust typically involves controlling one or more legs on the fire pentagon, seen below. If all five criteria for the fire pentagon are met, ignition source, confinement, dispersion of dust particulate, combustibility of the dust, and oxygen, a combustible dust explosion can occur (OSHA, 2007). The most common remedy is the removal of the ignition source, but often there are unexpected ignition sources, such as static discharge. Therefore, it is ideal to control as many factors as is feasible. Combustible dust is not specifically regulated by OSHA, but can be cited against the general duty clause. There are industry standards from the National Fire Protection Agency and other agencies to help guide end users on managing combustible dust safely. 


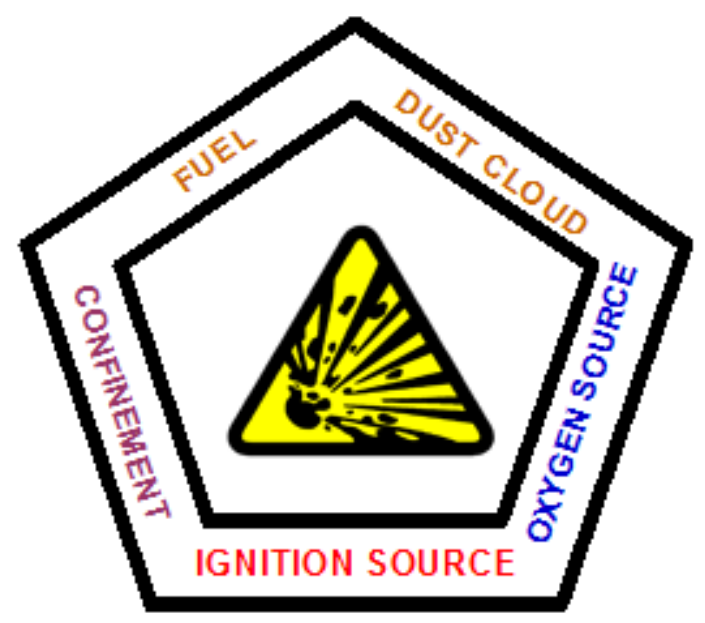

Figure 1.1 - Explosion Pentagon for Combustible Dust

\section{Health Hazards Associated with Common Additive Manufacturing Metal Powders}

The other main hazard with these materials comes from the health hazards associated with the inhalation of these materials. Aluminum, titanium, and magnesium do not constitute a high health risk. Other powders, such as nickel and chromium, are non-combustible and do not present a hazard from combustion. However, both are toxic and can present a considerable health risk. Nickel and chrome are sometimes added as a sub-alloy product as part of an aluminum or titanium alloy. These elements are increasingly being used as the main materials in an alloy. Two alloys common in the industry are Inconel 625 and Inconel 718 and are the alloys sampled in most of the sampling performed later in this paper. The typical publicly available compositions of these alloys are shown in Tables 1 and 2. 
Table 1.1 - Inconel 625 Chemical Composition, by \%

\begin{tabular}{|l|l|}
\hline Metal & \%Composition \\
\hline Nickel & $50.0-65.0$ \\
\hline Chromium & $17.0-21.0$ \\
\hline Iron & Balance \\
\hline Niobium (plus Tantalum) & $4.75-5.50$ \\
\hline Molybdenum & $2.80-3.30$ \\
\hline Titanium & $0.65-1.15$ \\
\hline Aluminum & $0.02-0.08$ \\
\hline Cobalt & $1.00 \max$ \\
\hline Carbon & $0.08 \max$ \\
\hline Manganese & $0.35 \max$ \\
\hline Silicon & $0.35 \max$ \\
\hline Phosphorus & $0.015 \max$ \\
\hline Sulfur & $0.015 \max$ \\
\hline Boron & $0.006 \max$ \\
\hline Copper & $0.30 \max$ \\
\hline
\end{tabular}

Table 1.2 - Inconel 718 Chemical Composition, by \%

\begin{tabular}{|l|l|}
\hline Metal & \%Composition \\
\hline Nickel & $58.0 \mathrm{~min}$ \\
\hline Chromium & $20.0-23.0$ \\
\hline Iron & $5.00 \mathrm{max}$ \\
\hline Molybdenum & $8.00-10.0$ \\
\hline Niobium (plus Tantalum) & $3.15-4.15$ \\
\hline Cobalt & $1.00 \mathrm{max}$ \\
\hline Manganese & $0.50 \max$ \\
\hline Silicon & $0.50 \max$ \\
\hline Phosphorus & $0.015 \max$ \\
\hline Sulfur & $0.015 \max$ \\
\hline Aluminum & $0.40 \max$ \\
\hline Titanium & $0.40 \max$ \\
\hline Carbon & $0.10 \max$ \\
\hline
\end{tabular}

When performing exposure monitoring, based on the metal percentages in the alloys, one would expect to find nickel to be the most abundant element, then chromium. Many of the trace elements are not sampled for and not considered when assessing toxicity, due to the low percent 
composition and relatively low toxicity. One notable exception to this is cobalt, which has a low exposure limit. Below in Table 3 are a list of Occupational Exposure Limits (OEL) used at COMPANY. Generally, these limits follow the American Conference of Governmental Industrial Hygienists (ACGIH) industry standard Threshold Limit Values (TLVs). In some instances, these internal OELs can be lower or higher than the TLV, depending on a few factors including toxicity, applicability, and practicability. Internal OELs are always lower or the same as the Occupational Safety and Health Administration (OSHA) Permissible Exposure Limits (PEL), to maintain compliance with OSHA. All the exposure limits listed below are for total dust fraction:

Table 1.3 - List of Occupational Exposure Limits of Materials in Nickel Alloys

\begin{tabular}{|l|c|}
\hline Element & OEL \\
\hline Aluminum & $10 \mathrm{mg} / \mathrm{m}^{3}$ \\
\hline Chromium & $0.5 \mathrm{mg} / \mathrm{m}^{3}$ \\
\hline $\begin{array}{l}\text { Chromium, hexavalent } \\
\text { compounds, all forms (as Cr) }\end{array}$ & $0.25 \mathrm{ug} / \mathrm{m}^{3}$ \\
\hline Cobalt & $0.02 \mathrm{mg} / \mathrm{m}^{3}$ \\
\hline Copper & $1 \mathrm{mg} / \mathrm{m}^{3}$ \\
\hline Iron & $5 \mathrm{mg} / \mathrm{m}^{3}$ \\
\hline Magnesium & $10 \mathrm{mg} / \mathrm{m}^{3}$ \\
\hline Manganese & $0.05 \mathrm{mg} / \mathrm{m}^{3}$ \\
\hline Nickel & $1 \mathrm{mg} / \mathrm{m}^{3}$ \\
\hline Nickel Compounds & $0.1 \mathrm{mg} / \mathrm{m}^{3}$ \\
\hline Silicon & $10 \mathrm{mg} / \mathrm{m}^{3}$ \\
\hline Titanium & $10 \mathrm{mg} / \mathrm{m}^{3}$ \\
\hline
\end{tabular}

The two major components of these alloys - nickel and chrome, also have some of the lower exposure limits as seen above. Some rationale for these exposure limits: Nickel can cause irritation of eyes, skin and respiratory tract. Skin contact to nickel can cause skin sensitization and allergic contact dermatitis. Chronic overexposures can cause perforation of the nasal septum, respiratory sensitization, asthma, inflammation of the nasal passages (sinusitis), and scarring of the lungs (pulmonary fibrosis). It is also listed as possibly carcinogenic to humans by IARC (Group 2B). Nickel compounds, including nickel oxides, have a lower OEL due to the association to lung cancer, cancer of the vocal cords and nasal cancer. (ACGIH 2001). Due to the potential for nickel to easily oxidize in small powder form, a conservative approach is taken to 
treat all AM nickel powders as nickel compounds - using the OEL of .1 mg/m3. The National Institute for Occupational Safety and Health (NIOSH) also employs a much more conservative limit of TWA Ca $0.015 \mathrm{mg} / \mathrm{m} 3$ due to the association with lung and sinus cancers.

Chrome is a skin irritant and eye irritant. It is also a severe respiratory tract irritation, and can cause lung damage, liver damage, kidney damage at higher chronic doses. Hexavalent chrome has also been found in some of the AM processes. Hexavalent chrome is typically formed when performing "hot work" - such as welding on chrome metal. The high temperatures involved in these processes can result in oxidation which converts the chrome to its hexavalent state. (OSHA 2009). Since AM processes are performed at similar high temperatures, it is theorized that some of the powder is converted into hexavalent chrome during this step. Hexavalent chrome is listed as "known to be a human carcinogen" by the NTP. Listed as carcinogenic to humans by IARC (Group 1), as causing lung cancer, nasal cancer and cancer of the gastrointestinal tract. Hexavalent chrome can also cause perforation of the nasal septum, respiratory sensitization, asthma, the accumulation of fluid in the lungs (pulmonary edema), lung damage and kidney damage (HSDB).

Secondary alloy components can also present health hazards. As the industry begins to branch out to different alloy compositions, new elements are introduced into processes which presents additional risk. When substituting out one material for another in any process, additional exposure concerns can develop. For example, the lower OEL of some secondary elements, such as cobalt, can cause overexposure to employees in a process that previously did not have overexposures due to the use of a less toxic alloy. Cobalt, vanadium and manganese are a few common elements that have higher risk profiles based on the toxicity and lower OELs. The alloys listed above - Inconel 718 and Inconel 625 both have a very low percentage of these two elements. However, newer alloys can potentially have a much larger percentage of these elements.

One of the difficulties in controlling exposure to AM metal powders is due to the lack of literature and knowledge around AM processes due to how rapidly the processes are expanding. Manufacturers, with limited knowledge on the subject, typically recommend employees to overprotect when using their equipment/powders. Overprotection with respirators can be an issue during AM processes, creating additional hazards such as ergonomic stress, heat stress, and 
reduced visibility. In addition, some manufacturers have implemented dust control solutions into AM machines, but these efforts can be misguided. One such example of this is a "comfort light", a light that comes on to indicate when an employee needs to wear a respirator based on the concentration of dust in the air. This can be misleading due to distance from the breathing zone and inconsistency. Traditional industrial hygiene practices of monitoring and exposure evaluation can better determine exposure and appropriate controls. The data collected in this paper is used to better understand the AM metal powder exposure potential.

\section{Additional EHS Risks in Additive Manufacturing}

There are also EHS risks present with AM processes that are outside of the big two mentioned, combustible dust and metal powder exposure. Argon and nitrogen gas are used to inert processes for quality and safety reasons, which present oxygen deficiency hazards. These are controlled through engineering controls; one example is logic in the PLC to prevent people from entering the processes rooms in case of a leak. Oxygen monitors are also in all the process rooms where argon and nitrogen gas are used. Lock tag and verify procedures utilizing double block and bleed methods of energy isolation also ensures that there is minimal risk for argon leak during the times when employees need to enter the process rooms.

Solvent exposure is another concern from a toxicity standpoint. Isopropyl alcohol (IPA) is used in all the major process areas - to clean metal dust and to polish metal samples/products. As some of the cleaning occurs in enclosed spaces, the IPA fumes can build up - and exposure monitoring has shown significant levels of IPA. The control implemented here was to use a 1015-foot pole with a pad on the other end of the pole to help clean Inconel powder from the walls of the atomizing chamber. Other IPA exposure hazards have been shown to be insignificant, qualitatively measured with a hand-held photoionization detector. The flammability risk is mitigated through proper bonding and grounding, and proper storage of the IPA in flammable cabinets.

In addition, one of the $3 \mathrm{D}$ printers utilized a solvent based binder - with a relatively high toxicity. To control this, a ventilation system was designed and implemented to carry the binder from the fan on the back of the machine - connect into existing ductwork - and out through the roof. Later, during the process, this material was substituted out with a water-based binder to eliminate the potential for overexposure. Other hazard potential sources include non-ionization 
radiation (EMF and lasers), electrical and mechanical hazards, ergonomics, mobile equipment and molten metal. 


\section{Chapter 2: Methods}

\section{Sampling Strategy}

COMPANY takes a traditional approach to industrial hygiene when deciding on sampling methodology and determining what sampling should be prioritized. what to sample for. This prioritized sampling plan prioritized by various factors including \# of samples already taken, toxicity of analyte, date of last sampling, and availability. Balancing a plan at a research and development facility has its own challenges compared to traditional manufacturing facilities, due to the transient nature of the work and the variable work schedules. Some of the highest exposure tasks at this facility are tasks that only occur several times a year, so efforts must be coordinated to ensure sampling is done on time. In addition, some of the tasks occur with very little prior notice, so sampling can be difficult to obtain in certain situations.

A risk-based approach is taken when determining the prioritized sampling plan. When new processes are developed and the exposure is unknown, sampling is typically performed during the first couple of trials during the startup of a new process. For some of the processes in additive manufacturing, one sample or a qualitative assessment is sufficient to classify the Significant Exposure Group (SEG) as "insignificant" - or less than 50\% of the OEL. Some instances of this include when the sample comes back close or below the limit of detection (LOD) or when sufficient controls are in place that a qualitative assessment can ensure limited exposure to the employee.

For other processes, sampling sometimes showed a potential for a "significant" exposure (e.g., an exposure between $50 \%$ to $100 \%$ of the OEL) or an "unacceptable" exposure (e.g., an exposure above the OEL). In these situations, additional monitoring is to be performed to gather sufficient data to make a sufficiently accurate assessment. This also allows workplace practices to become better established and ensure that the exposure potential is less variable from day to day.

\section{Task Descriptions}

Binder-Jet AM printer operation wand cleanout with nickel powder Binder-Jet additive printers are used to print products with nickel and chrome based 
powder. Employee interface with these printers includes removing samples and loading powder into the feeder via a handheld scoop. The highest source of exposure potential comes from the cleanout of the build stage where loose powder is brushed to clean the build stage and to recover the part. There is no local exhaust ventilation for this process.

\section{Laser AM printer operation machine cleanout}

A build chamber is opened and powder on the build plate is brushed into the collector. This is a detailed process which requires hand brushing of the approximately 6 square foot enclosure This creates visible dust clouds near the employee. The powder in the collector is scooped and sieved by hand inside the printer to filter out larger particles. There is no fixed local exhaust ventilation, however a portable combustible dust approved vacuum is used to help collect fugitive dust. The task takes approximately one hour and only needs to be done once a day, limiting the exposure potential.

\section{Sieving powder operations:}

IN625 and other nickel powders are sieved to determine particle size consistency and to prepare analytical samples. Sieving is performed to separate nickel powder into different particle size distributions. Exposure comes from extracting powder from filters with a handheld scoop, weighing powder, and transferring the powder to vials with a handheld scoop. Task is performed in a lab hood. Common to process multiple sets of filters in a day - so there is potential for the task to last most of the day depending on workload as the task is highly variable.

\section{Sample Preparation - Homogenizing bottles of powder}

A large powder bottle is opened and material is poured and hand scooped into smaller bottles. Bottles are then rotated on a mixer to homogenize the powder. Powder is poured/scooped into additional bottles, homogenized a second time, and then poured into a larger container for storage. Common to process multiple sets of filters in a day - so there is potential for the task to last most of the day depending on workload as the task is highly variable. The exposure potential comes from the high frequency of hand scooping powder from one container to another using a slow controlled pour. Most of the powder transfers occur within the lab hood. Transferring powder to the mixer is not done within a lab hood due to the large size of the mixer. 


\section{Nickel atomization cleanout and maintenance}

Nickel atomizer requires cleanout and maintenance after a run to retrieve the powder and prep the atomizer for the next run. The powder is collected in a hopper and powder transfer is required to remove some of the powder from the hopper for analysis. Powder builds on the chamber walls and other areas of the process that must be cleaned by hand with rags and isopropyl alcohol. There is no local exhaust ventilation for this task. Task is currently respirator required.

\section{Sampling Methodology}

Sampling was performed with MSA Escort Electronic Laminar Flow (ELF) personal sampling pumps. These pumps were calibrated to various flow rates depending on the minimum volume required. For long-term (full shift) exposure monitoring - typically $2.0 \mathrm{~L} / \mathrm{min}$ was used. However, many of the sampling events fall in between short term exposure monitoring and fullshift monitoring. For short term sampling, higher flows rates were used to meet the minimum volume expectation, no higher than $3.0 \mathrm{~L} / \mathrm{min}$. These flow rates were calibrated prior to the sampling event the day with a BIOS DryCal. The pumps were pre and post calibrated, all calibrations were done in the IH laboratory on site. A sampling train was assembled to collect hexavalent chromium and metal particulate. The sampling train consisted of a calibrated pump typically attached to an employee's belt or pocket, tygon tubing, and an open-faced or closedfaced $37 \mathrm{~mm}$ filter cassette.

Cassette placement is aimed to accurately capture exposure, by placing the cassette near the employees breathing zone. For certain tasks, employees wear powered air purifying respirators (PAPR). To monitor these tasks, the cassettes are placed on the skirt of the PAPR helmet near the breathing zone, marked by $\mathrm{X}$ on the below figure. 


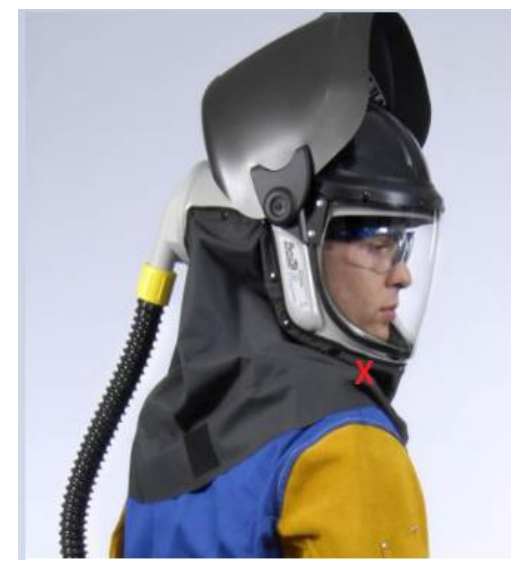

Figure 2.1 - Cassette Placement on PAPR.

Hexavalent chrome samples were collected on a $37 \mathrm{~mm} 2 \mathrm{pc}$ cassette $\mathrm{w} / 5.0 \mathrm{um}$ pore size) poly-vinyl chloride (PVC) filter cassettes. Chrome, nickel, and other metal element samples were collected on $37 \mathrm{~mm}$ 2pc Cassette w/ 0.8um mixed cellulose ester (MCE) cassettes. All cassettes are pre-weighed by the laboratory so that gravimetric analysis can be performed for total dust. A blank or two blanks were also collected during the day of sampling, depending on the number of samples taken. These cassettes are then shipped back to the laboratory within a week of the sampling event. Due to the stability of the hexavalent chrome samples, samples are typically sent within the same day of sampling to prevention sample degradation. Table 2.1 below shows the reference method, flow rate (TWA), media name, and the OEL compared to.

Table 2.1 - Sampling Analyte Parameters

\begin{tabular}{|l|l|l|l|}
\hline Parameter & Hexavalent Chromium & Chrome(III) & Nickel \\
\hline Reference Method & $\begin{array}{l}\text { O-215 - OSHA - } \\
\text { IC/Colorimetric for } \\
\text { hexavalent chromium }\end{array}$ & $\begin{array}{l}\text { A-I86-155 - } \\
\text { COMPANY - } \\
\text { ICP/AA for metals }\end{array}$ & $\begin{array}{l}\text { A-I86-155 - } \\
\text { COMPANY - ICP/AA } \\
\text { for metals }\end{array}$ \\
\hline Flow Rate (TWA) & $2.0 \mathrm{LPM}$ & $2.0 \mathrm{LPM}$ & $2.0 \mathrm{LPM}$ \\
\hline Media Name & $\begin{array}{l}37 \mathrm{~mm} 2 \mathrm{pc} \text { Cassette w/ } \\
5.0 \mathrm{um} \text { PVC Filters }\end{array}$ & $\begin{array}{l}37 \mathrm{~mm} 2 \mathrm{pc} \mathrm{Cassette} \\
\text { w/ } 0.8 \mathrm{um} \mathrm{MCE}\end{array}$ & $\begin{array}{l}37 \mathrm{~mm} 2 \mathrm{pc} \mathrm{Cassette} \mathrm{w/} \\
0.8 \mathrm{um} \mathrm{MCE}\end{array}$ \\
\hline OEL - TWA & $0.25 \mathrm{ug} / \mathrm{m}^{3}$ & $0.5 \mathrm{mg} / \mathrm{m}^{3}$ & $0.1 \mathrm{mg} / \mathrm{m}^{3}$ \\
\hline
\end{tabular}




\section{Chapter 3: Results}

\section{Exposure Monitoring Results and Statistics}

Personal air samples were taken on various employees for the various tasks that use additive manufacturing powders. A total of 8 different employees were sampled across the different tasks for a total number of 17 samples. Samples were taken based on the risk profile and the frequency of task. Total of number of samples by task are shown as Table 3.1:

Table 3.1 - Samples Taken Per Task.

\begin{tabular}{|l|c|}
\hline Task: & Samples taken: \\
\hline Nickel atomization cleanout & 6 \\
\hline Laser AM printer operation and cleanout & 3 \\
\hline Binder-Jet AM printer Operation and cleanout & 2 \\
\hline Sample prep - Homogenizing bottles of powder & 2 \\
\hline Sieving Powder Operations & 4 \\
\hline
\end{tabular}

All the samples are being compared to the Time Weighted Average (TWA) exposure limits due to the length of sampling. The COMPANY Occupational Exposure Limits (OELs) and the OSHA Permissible Exposure Limits (PELs) that are applicable to the sampling are below. The COMPANY OELs will be used to determine to internal compliance in the subsequent calculations.

Table 3.2 - Exposure Limits Per Analyte

\begin{tabular}{|l|c|c|l|}
\hline Element & $\begin{array}{c}\text { COMPANY } \\
\text { OEL }\end{array}$ & $\begin{array}{c}\text { OSHA } \\
\text { PEL }\end{array}$ & Units \\
\hline Chromium & 0.5 & 1.0 & $\mathrm{mg} / \mathrm{m}^{3}$ \\
\hline $\begin{array}{l}\text { Chromium, hexavalent } \\
\text { compounds, all forms (as Cr) }\end{array}$ & 0.25 & 5.0 & $\mathrm{ug} / \mathrm{m}^{3}$ \\
\hline Nickel/Nickel Compounds & 0.1 & 1.0 & $\mathrm{mg} / \mathrm{m}^{3}$ \\
\hline Total Dust & 10 & 15 & $\mathrm{mg} / \mathrm{m}^{3}$ \\
\hline
\end{tabular}

All employees work 8-hour shifts. The time-weighted average calculations were performed using this assumption. Most samples taken during this sampling campaign were not full shift samples, due to the tasks having no exposure during non-sampled times. For example, 
when a machine is operating in an enclosed environment, employees are isolated from the exposure source, so no sampling is performed. All samples are considered to have zero exposure outside of the sampling period for the work shift. To compare to these results to internal compliance standards the \% OEL is used. This is the percentage of the OEL the exposure session indicates, time weighted over the eight-hour shift. This is calculated by the following equation:

$$
\% O E L=\frac{\text { Timeof } \text { exposure monitoring }}{480} \times \frac{\text { Monitoring Re sult }}{\text { Occupational Exposure Limit }}
$$

The samples are split into three different categories: (1) lab scale operations (homogenizing bottles of powder, sieving powder operations), (2) additive manufacturing printing (binder-jet AM printer operation/cleanout and laser AM printer operation and cleanout), and (3) the nickel atomization process. There are similarities between tasks in the groups, and similar personnel performing these operations.

Table 3.3 shows the data for AM printing operations. Rows with the same sample number are part of the same sample, but each row is dedicated to a different analyte. Hex Chrome is used as an abbreviation for Hexavalent Chrome. Sample number 1 and 2 are for the binder-jet AM printer operation. Sample 3,4, and 5 are for laser AM printer operation. Raw compiled sampling data can be found in Appendix A and Appendix B. This includes data missing from some of the data below, including employee name and sampling time, due to formatting. Samples are numbered chronologically by task. 
Table 3.3 - Sampling Data for Additive Manufacturing Printing Operations

\begin{tabular}{|c|c|c|c|c|c|c|c|c|}
\hline $\begin{array}{l}\text { Sample } \\
\text { Number }\end{array}$ & Task & Analyte & Result & OEL & Units & $\begin{array}{c}\text { \%OEL } \\
\text { PRE-TWA }\end{array}$ & $\%$ OEL & $\begin{array}{c}\text { Sampling } \\
\text { time } \\
\text { (minutes) }\end{array}$ \\
\hline 1 & Binder Jet Cleanout & $\begin{array}{l}\text { Hex. } \\
\text { Chrome }\end{array}$ & $<0.027$ & 0.25 & $\mathrm{ug} / \mathrm{m}^{3}$ & $<10.8 \%$ & $<8.26 \%$ & 367 \\
\hline 1 & Binder Jet Cleanout & Total Dust & 0.0203 & 10 & $\mathrm{mg} / \mathrm{m}^{3}$ & $0.20 \%$ & $0.16 \%$ & 367 \\
\hline 2 & Binder Jet Cleanout & Nickel & 0.0016 & 0.1 & $\mathrm{mg} / \mathrm{m}^{3}$ & $1.60 \%$ & $1.30 \%$ & 390 \\
\hline 2 & Binder Jet Cleanout & Total Dust & 0.025 & 10 & $\mathrm{mg} / \mathrm{m}^{3}$ & $0.25 \%$ & $0.20 \%$ & 390 \\
\hline 3 & Laser printer cleanout & Total dust & 0.47 & 10 & $\mathrm{mg} / \mathrm{m}^{3}$ & $4.70 \%$ & $1.08 \%$ & 110 \\
\hline 4 & Laser printer cleanout & \begin{tabular}{|l|} 
Hex. \\
Chrome \\
\end{tabular} & 0.16 & 0.25 & $\mathrm{ug} / \mathrm{m}^{3}$ & $64.0 \%$ & $8.93 \%$ & 67 \\
\hline 4 & Laser printer cleanout & Dust, total & 0.22 & 10 & $\mathrm{mg} / \mathrm{m}^{3}$ & $2.20 \%$ & $0.31 \%$ & 67 \\
\hline 5 & Laser printer cleanout & Dust, total & 0.62 & 10 & $\mathrm{mg} / \mathrm{m}^{3}$ & $6.20 \%$ & $0.31 \%$ & 24 \\
\hline 5 & Laser printer cleanout & Nickel & 0.095 & 0.1 & $\mathrm{mg} / \mathrm{m}^{3}$ & $95.0 \%$ & $4.75 \%$ & 24 \\
\hline
\end{tabular}

Both sample 1 and 2 are for the Binder-Jet AM printer cleanout and operation. Sample 1's hexavalent chrome result was below the analytical detection limit. This was most likely due to the small amount of particulate collected. Both sample one and two had very minimal exposure, and the task was deemed as "insignificant", being below $50 \%$ of the OEL over an 8 hour shift. Therefore, this task was not sampled further. These results show that the Binder-Jet AM printer cleanout and operation does not pose a significant health risk - even if the task was expanded to multiple machines/cleanouts per day.

For the laser AM processes, exposure results showed higher values. Sample 3 was only analyzed for total dust as at the time aluminum powder was being used. The total dust results for the 3 samples were within the same order of magnitude for each of the tasks. Sample 4 was analyzed for hexavalent chrome, and reached $64 \%$ of the OEL prior to time weighting. However, due to the short task duration, 67 minutes, the exposure for the full shift after time weighting was in the "insignificant" range. A similar scenario occurs for the nickel in sample number 5. Due to the short duration of the tasks, and lack of significant exposures observed, this task does not need to be samples further. These results show that for the laser AM printer cleanout and operation, there may be potential for an overexposure if the task was expanded to multiple machine cleanouts, or if a more thorough cleanout was needed.

Table 4 below shows the data for the lab scale powder operations. Sample numbers 6, 7, 
8 and 9 are for the sieving powder operations. Sample 10 and 11 are for the homogenization of powder task.

Table 3.4 - Sampling Data for Lab Scale Operations

\begin{tabular}{|c|l|l|r|r|l|r|r|c|}
\hline $\begin{array}{c}\text { Sample } \\
\text { Number }\end{array}$ & Task & \multicolumn{1}{|c|}{ Analyte } & Result & OEL & \multicolumn{1}{c|}{ Units } & $\begin{array}{c}\text { \% OEL } \\
\text { PRE-TWA }\end{array}$ & \% OEL & $\begin{array}{c}\text { Sampling time } \\
\text { (minutes) }\end{array}$ \\
\hline 6 & Sieving & Hex. Chrome & 0.053 & 0.25 & $\mathrm{ug} / \mathrm{m}^{3}$ & $21.2 \%$ & $10.6 \%$ & 230 \\
\hline 6 & Sieving & Dust, total & 0.04 & 10 & $\mathrm{mg} / \mathrm{m}^{3}$ & $0.40 \%$ & $0.19 \%$ & 230 \\
\hline 7 & Sieving & Hex. Chrome & 0.085 & 0.25 & $\mathrm{ug} / \mathrm{m}^{3}$ & $34.0 \%$ & $7.93 \%$ & 112 \\
\hline 7 & Sieving & Dust, total & 0.21 & 10 & $\mathrm{mg} / \mathrm{m}^{3}$ & $2.10 \%$ & $0.49 \%$ & 112 \\
\hline 8 & Sieving & Chrome(III) & 0.038 & 0.5 & $\mathrm{mg} / \mathrm{m}^{3}$ & $7.60 \%$ & $2.85 \%$ & 180 \\
\hline 8 & Sieving & Dust, total & 0.32 & 10 & $\mathrm{mg} / \mathrm{m}^{3}$ & $3.20 \%$ & $1.20 \%$ & 180 \\
\hline 8 & Sieving & Nickel & 0.1 & 0.1 & $\mathrm{mg} / \mathrm{m}^{3}$ & $100 \%$ & $37.5 \%$ & 180 \\
\hline 9 & Sieving & Chrome(III) & 0.044 & 0.5 & $\mathrm{mg} / \mathrm{m}^{3}$ & $8.80 \%$ & $3.30 \%$ & 180 \\
\hline 9 & Sieving & Dust, total & 0.19 & 10 & $\mathrm{mg} / \mathrm{m}^{3}$ & $1.90 \%$ & $0.71 \%$ & 180 \\
\hline 9 & Sieving & Nickel & 0.12 & 0.1 & $\mathrm{mg} / \mathrm{m}^{3}$ & $120 \%$ & $45.0 \%$ & 180 \\
\hline 10 & Homogenizing & Dust, total & 0.18 & 10 & $\mathrm{mg} / \mathrm{m}^{3}$ & $1.80 \%$ & $0.41 \%$ & 108 \\
\hline 10 & Homogenizing & Nickel & 0.038 & 0.1 & $\mathrm{mg} / \mathrm{m}^{3}$ & $38.0 \%$ & $8.55 \%$ & 108 \\
\hline 11 & Homogenizing & Hex. Chrome & 0.0033 & 0.5 & $\mathrm{mg} / \mathrm{m}^{3}$ & $0.66 \%$ & $0.17 \%$ & 127 \\
\hline 11 & Homogenizing & Dust, total & 0.053 & 10 & $\mathrm{mg} / \mathrm{m}^{3}$ & $0.53 \%$ & $0.14 \%$ & 127 \\
\hline 11 & Homogenizing & Nickel & 0.0033 & 0.1 & $\mathrm{mg} / \mathrm{m}^{3}$ & $3.30 \%$ & $0.87 \%$ & 127 \\
\hline
\end{tabular}

Three samples were taken for both nickel and hexavalent chrome. Two samples are taken for trivalent chrome, both results are below $10 \%$ of the OEL. Both samples 8 and 9 are above the $100 \%$ OEL for nickel before time weighting. If this task occurred for the full shift, these samples would be overexposures. After time weighting the results, both samples were below $50 \%$ of the $\%$ OEL. Based on these results, it is essential to ensure that these tasks are not performed for the full shift. Any change in task procedure is critical to communicate - especially for lab scale operations as they are easy to scale up based on process demands. Other differences in procedure, such as use of a malfunctioning lab hood, would also contribute to potential overexposure, so it is important to ensure that proper controls are in place.

The hexavalent chrome result from sample 7 is below the detection limit. Note that the detection limit value is much higher in this case than sample 1 above. Sample 1 was sampled for 367 minutes, leading to a much larger total air volume than sample 7 , which was only sampled 
for 112 minutes. The smaller total air volume provides less analytical resolution.

Table 3.5 below shows the data associated with the nickel atomizer cleanout. All samples are for the nickel atomizer cleanout. Samples 12 and 13 were analyzed for hexavalent chrome, the rest of the samples were analyzed for nickel and chrome(III).

Table 3.5 - Sampling data for Nickel Atomizer Cleanout

\begin{tabular}{|c|l|r|r|l|r|r|r|}
\hline $\begin{array}{c}\text { Sample } \\
\text { Number }\end{array}$ & \multicolumn{1}{|c|}{ Analyte } & Result & OEL & Units & $\begin{array}{c}\text { \%OEL } \\
\text { PRE-TWA }\end{array}$ & \%OEL & $\begin{array}{c}\text { Sampling time } \\
\text { (minutes) }\end{array}$ \\
\hline 12 & Hex. Chrome & $<0.049$ & 0.25 & $\mathrm{ug} / \mathrm{m}^{3}$ & $<19.6 \%$ & $6.74 \%$ & 165 \\
\hline 12 & Dust, total & 1.3 & 10 & $\mathrm{mg} / \mathrm{m}^{3}$ & $13.0 \%$ & $4.47 \%$ & 165 \\
\hline 13 & Hex. Chrome & $<0.047$ & 0.25 & $\mathrm{ug} / \mathrm{m}^{3}$ & $<18.8 \%$ & $6.70 \%$ & 171 \\
\hline 13 & Dust, total & 1 & 10 & $\mathrm{mg} / \mathrm{m}^{3}$ & $10.0 \%$ & $3.56 \%$ & 171 \\
\hline 14 & Chrome(III) & 0.11 & 0.5 & $\mathrm{mg} / \mathrm{m}^{3}$ & $22.0 \%$ & $4.86 \%$ & 106 \\
\hline 14 & Dust, total & 0.99 & 10 & $\mathrm{mg} / \mathrm{m}^{3}$ & $9.90 \%$ & $2.19 \%$ & 106 \\
\hline 14 & Nickel & 0.33 & 0.1 & $\mathrm{mg} / \mathrm{m}^{3}$ & $330 \%$ & $72.8 \%$ & 106 \\
\hline 15 & Chrome(III) & 2.2 & 0.5 & $\mathrm{mg} / \mathrm{m}^{3}$ & $440 \%$ & $95.3 \%$ & 104 \\
\hline 15 & Dust, total & 13 & 10 & $\mathrm{mg} / \mathrm{m}^{3}$ & $130 \%$ & $28.17 \%$ & 104 \\
\hline 15 & Nickel & 6.9 & 0.1 & $\mathrm{mg} / \mathrm{m}^{3}$ & $6900 \%$ & $1495 \%$ & 104 \\
\hline 16 & Chrome(III) & 0.063 & 0.5 & $\mathrm{mg} / \mathrm{m}^{3}$ & $12.6 \%$ & $1.94 \%$ & 74 \\
\hline 16 & Dust, total & 1.3 & 10 & $\mathrm{mg} / \mathrm{m}^{3}$ & $13.0 \%$ & $2.00 \%$ & 74 \\
\hline 16 & Nickel & 0.19 & 0.1 & $\mathrm{mg} / \mathrm{m}^{3}$ & $190 \%$ & $29.3 \%$ & 74 \\
\hline 17 & Chrome(III) & 0.028 & 0.5 & $\mathrm{mg} / \mathrm{m}^{3}$ & $5.60 \%$ & $0.85 \%$ & 73 \\
\hline 17 & Dust, total & 1.2 & 10 & $\mathrm{mg} / \mathrm{m}^{3}$ & $12.0 \%$ & $1.83 \%$ & 73 \\
\hline 17 & Nickel & 0.087 & 0.1 & $\mathrm{mg} / \mathrm{m}^{3}$ & $87.0 \%$ & $13.2 \%$ & 73 \\
\hline
\end{tabular}

Two samples were taken for hexavalent chrome, while four samples were taken for nickel/chrome (III). Both the hexavalent chrome samples are below the detection limit. The chrome results are also all insignificant, due to the higher exposure limit. Samples 14, 15 and 16 are above the \% OEL for nickel prior to time weighting. Sample 17 is in the significant range of exposure as well. If this task occurred for the full shift with the same level of exposure, both samples 14 and 16 would be considered an overexposure. After time weighting the results, both samples were below the \%OEL. Sample 14, after time weighting the result, is still within the 'significant range' (>50\%) of the OEL.

Sample 15's results are much higher than the rest of the data set. This sample differed 
from the other samples taken, as this sample was taken on a contractor that was performing the task for the first time, without an established procedure. This task, sieving the particles from the nickel atomizer, has been automated out. This task is not captured in any other of the samples taken, therefore is excluded from this similar exposure group. I

Using this data, the confidence interval can be used to determine the probability of an exposure being in the unacceptable range. The confidence interval can be calculated by the below formula, with $\overline{\mathrm{x}}$ being the arithmetic mean, $\mathrm{t}$ being the confidence coefficient, $\mathrm{s}$ being the standard deviation, and $\mathrm{n}$ being the sample size. The values are calculated below in Table 3.6.

$$
\overline{\mathrm{X}} \pm t \frac{\mathrm{s}}{\sqrt{\mathrm{n}}}
$$

Where: $\quad \overline{\mathrm{x}}=$ arithmetic mean,

$$
\begin{aligned}
& \mathrm{t}=\text { confidence coefficient } \\
& \mathrm{s}=\text { standard deviation } \\
& \mathrm{n}=\text { sample size }
\end{aligned}
$$

\section{Table 3.6 - Nickel Exposure Data Confidence Interval}

\begin{tabular}{|l|c|}
\hline Parameter & Value \\
\hline$\overline{\mathbf{x}}$ & $38.4 \%$ \\
\hline $\mathbf{t}(.95)$ & 4.30 \\
\hline $\boldsymbol{\sigma}$ & $30.9 \%$ \\
\hline $\mathbf{n}$ & 3 \\
\hline Lower Bound: & $-38.2 \%$ \\
\hline Upper bound: & $115 \%$ \\
\hline Confidence interval: & $38.4 \% \pm 76.6 \%$ \\
\hline
\end{tabular}

The upper bound represented for the $95 \%$ confidence interval above, $115 \%$ of the OEL, suggest that additional sampling is needed. With additional data, this analysis will be more useful as there will be more statistical resolution. The variability of $R \& D$ can potentially change a process significantly, a factor these calculations don't account for. More sampling data will provide greater statistical confidence that employees do not have overexposure potential. Additional sampling is planned to help further characterize this task. 


\section{Chapter 4: Discussion}

\section{Controlling for AM Hazards and Hierarchy of Controls}

The results showed 1 sample above 50\% of the OEL, with a nickel atomizer cleanout sample at $72.8 \%$ of the OEL. 3 Samples are within the $25 \%-50 \%$ range of the OEL, 2 samples for the sieving operation, and another for the nickel atomizer cleanout. However, there is little evidence that supports any of the SEGs being classified as overexposures. Changes to the operation, such as an increase of the nickel concentration in an alloy, could lead to higher exposures. Controlling these changes is made more difficult by the frequent changes that occur within a R\&D setting. The need to balance a fast pace of work while ensuing employee safety and health is a challenging balance to obtain. A multi-layered approach is taken to determine additional hazards. Before any process is put into place, this facility uses a project management system that includes the use of an EHS review and the use of a tool called a Project Environmental Health and Safety Review or PEHSR. The PEHSR is essentially a guided checklist to help EHS and the process partner determine what the main EHS risks are for a new project. The checklist helps guides future action items and is on the forefront of determine proper controls for these processes to help mitigate exposure and combustible dust risk.

Once the project is fully reviewed and commissioning is finished, even for a wellcontrolled project there are still risks. Most of these come from the frequent change that a project/process can have due to the $\mathrm{R} \& \mathrm{D}$ nature of the site. It is important to control for these changes due to the potential hazards they present. Some hazards include change in alloy material, change in process procedure, and change in equipment. Prior to bringing any new material on site a new material review is performed. This review is an EHS risk assessment of how the material will be used. A qualitative exposure assessment is also assigned, and if acceptable the material is brought on site. If the initial exposure assessment indicated an unknown or significant exposure, further evaluation will be performed. This allows the site to ensure that the frequent change in materials is not causing any unanticipated exposure effects. If this review is not performed, the material will be held up by logistics, and the material will be subject for review before brought on site.

The site also uses a change management procedure to ensure that significant changes to the process do not bring any uninvited EHS risk. A significant change is defined as one that 
changes the process that could have unintended effects, such as a change in operating procedure, use of a new alloy, or replacing a part of the equipment. The change management form includes the details and reason for proposed change, review by the lead engineer, list of action items generated from the review, and approval signoffs for EHS and operations manager.

The PEHSR and other project review methodology allows elimination, substitution, and engineering controls to be implemented prior to any project work being completed. At the cost of time and money up front, potential EHS issues can be solved on the front end of a project, lessening the potential for issues while the project is running. The industrial hygiene hierarchy of controls is utilized at our site. Some of these controls are utilized to mitigate exposures in additive manufacturing and other areas on site. The first hierarchy control that COMPANY utilizes is substitution/elimination of the hazard. The main potential hazard that can be substituted out is the alloy itself. Beryllium, a common alloy metal in the aluminum industry, has been mostly substituted out of our site, used only in one specific application in very low concentrations. The use of beryllium has been substituted out for beryllium free alloys due to the high toxicity of beryllium. Potential alloys have also been tested in a way that prioritizes the less hazardous/ least combustible products. Not only does this benefit COMPANY's employees from a protection of hazard standpoint, but eliminates potential concerns if an alloy is to be scaled up or move into a production phase. This also applies to alloys with health hazards, such as limiting the concentration of cobalt to decrease the toxicological profile of an alloy.

The next layer on the hierarchy of controls are engineering controls. Engineering controls do not remove the exposure potential, but instead help to mitigate the effects of the hazard. One example of this is the use of a cleaning mechanism that reaches inside the atomizer to clean the sides. This allows the operator to clean the atomizer without going into the cylinder, avoiding potential additional exposure to metal powder and solvent as well as eliminating a potential fall hazard. The atomizer systems have also been designed to prevent minimum amount of free powder available, limiting cleanup and therefore exposure potential. One example of this is allowing the same deposit container for atomization being compatible with the sieving unit. Operators do not need to transfer powder from one container to another, minimizing exposure. The sieve unit is also fully automated, with only interaction coming during maintenance activities. Lab hoods and local exhaust ventilation is used to draw powder away from technicians during lab scale operations. Several ergonomic issues have also been engineered out, using tools 
and engineered solution to help technicians lift heavy crucibles and metal containers full of powders.

Administrative controls are used in conjunction with the above controls to ensure worker safety. All medium to high EHS risk tasks have safe work instruction associated with the task. This allows the employee to follow a set procedure to perform the task. In preventing exposure this is important because performing the task incorrectly may lead to a higher exposure due to improper work methods. Examples of this is using a step by step procedure to minimize a potential dust cloud, minimizing the amount of sieving required for a task, or ensuring that the operators are wearing the appropriate PPE during the task. During the nickel atomization cleanup, proper procedure including using a gentler sieving technique, the amount of dust cloud formation can be reduced and exposure lessened

Human factors can influence potential risk as well. Human performance, a study that takes a quantitative approach to human error prediction is used at our site to recognize when one is in an error likely situation and provide tools/training to help decrease errors that can lead to injury or illness, deficiencies in production or quality. In EHS, this help us predict and prevent errors that could occur which can lead to incident or overexposure. For example, pre-jobs going over a checklist of what will be required for the job and reviewing tasks that will be performed the job, helps mitigate some of the hazards associated with the task.

Training is also performed to ensure that employees learn the risk of the hazards they will be exposed to. For nickel and hex chrome, as well as combustible dust, employees working with these materials in additive manufacturing are given training on both subjects for awareness due to the hazard potential associated with these materials. When a new employee is brought on through the new hire process, or transferred to another division, a job analysis form is filled out by the supervisor for the employee. This form is reviewed by EHS, and the proper trainings are then assigned to the employee. Additional training outside of awareness training is given to employees who work in specific tasks - such as an operator in the nickel atomization room.

This also raises the issue of communication of the hazards to employees. With the number of alloys being created it was not feasible to create a SDS for each alloy due to time and budget constraints. An internal hazard communication spreadsheet was developed to communicate the hazards to employees. Essentially, it is a spreadsheet where employees mark 
off which elements are in the alloy, and the associated health effects are displayed, along with other data typically found on a SDS - such as first aid procedure. When sending a material off site, per OSHA Hazard Communication standard a SDS is created to communicate the hazards accurately. In addition, for new powders that are being transported - explosivity testing needs to be performed per DOT regulations to determine the shipping class.

The base of the control pyramid, PPE, is used as a last resort in many cases, or as a temporary measure until controls higher up on the control pyramid can be implemented. Powered air purifying respirators are used in some situation, such as the nickel atomizer room. Before any monitoring is done, a qualitative assessment is done. If this qualitative assessment indicates that there may be potential for exposure, PPE will be worn until that exposure is more accurately quantified. Our site follows all the requirements of OSHA, 1910.134, including fit tests and training for employees. Dust masks may also be worn on a voluntary basis, if the user has gone through annual respiratory protection training. Safety shoes and glasses are typically worn in all lab areas to prevent against common hazards/ eye exposure hazards. Flame resistant clothing is typically worn when dealing with combustible dust as well. 


\section{Chapter 5: Conclusion}

These results suggest that the current operations do not pose a risk for exposure above the occupational exposure limits and the OSHA permissible exposure limits. More sampling is needed for the nickel atomizer task to accurately quantify the exposure and provide more statistical resolution. Additional samples should also be taken for the sieving powder operations to more accurately quantify the exposure. Higher variability of exposure in an R\&D environment exists due to the nature of experimentation. Therefore, prior to establishing standardized work and refining confidence intervals in exposure it is necessary to provide layers of protection that can accommodate that variability.

These results also suggest that changes in the process, for example a scale up of powder used or a change in the alloy composition could lead to a higher exposure to employees. For example, adding $20 \%$ more chrome to an alloy composition would increase the exposure proportionally. This study will allow for communication between facilities to share lessons learned and knowledge on AM powder safety. Using this data and research in the study will provide a basis for a more comprehensive health and safety analysis of metal powder usage and creation.

\section{Future Efforts and Research Limitations}

There are many different directions this sampling and exploratory effort can take on. More samples should be taken for the nickel atomizer task to get a more representative baseline. There are also new operations that are coming online that will need to be sampled and characterized as advancement in AM continues. All the sampling was performed on similar alloy compositions, however if alloy compositions being to change, so may the sampling requirements and potential overexposes and controls. There is also the potential for evaluation of hazards at other facilities that could potentially utilize this technology. On a larger scale, some of these tasks could potentially be overexposures, so communicating this information to other facilities is important for employee protection. Titanium alloys may become a greater area of focus from an exposure standpoint as well. REACH in Europe is considering new regulation to treat all titanium exposure as titanium dioxide, a IARC 2B carcinogen.

The availability and time constraints on sampling are most likely the biggest research 
limitation available. With the ability to take more samples, more accurate data can be achieved. There are also processes that are not up and running, or do not occur often enough that sampling is feasible, exposure data for these processes would be beneficial. Another issue with managing industrial hygiene is the prioritization needed when performing sampling. If other high risk exposures need sampled or evaluated, this can take away from less prioritized sampling. 


\section{BIBLIOGRAPHY}

ACGIH: Documentation of the Threshold Limit Values (TLVs) and Biological Exposure Indices (BEIs) - Nickel and Inorganic Compounds, including Nickel Subsulfide. 2001.

Amon, C. H.; Beuth, J. L.; Weiss, L. E.; Merz, R.; Prinz, F. B. (1998). "Shape Deposition Manufacturing With Microcasting: Processing, Thermal and Mechanical Issues" (PDF). Journal of Manufacturing Science and Engineering. 120.

Lithner, D. (2011). Environmental and Health Hazards of Chemicals in Plastic Polymers and Products. Retrieved March 03, 2017, from https://gupea.ub.gu.se/bitstream/2077/24978/1/gupea_2077_24978_1.pdf

Hazard Prevention and Control in the Work Environment: Airborne Dust. (n.d.). WHO/SDE/OEH/99.14. Retrieved from http://www.who.int/occupational_health/publications/en/oehairbornedust3.pdf

HSDB: CHROMIUM COMPOUNDS. (n.d.). Retrieved April 27, 2017, from http://toxnet.nlm.nih.gov/cgibin/sis/search2/r?dbs\%2Bhsdb\%3A\%40term\%2B\%40DOCNO\%2B6999

Occupational Safety \& Health Administration [OSHA]. (2009). Publications (Hexavalent Chromium). Retrieved from https://www.osha.gov/Publications/OSHA-3373-hexavalentchromium.pdf

Occupational Safety \& Health Administration [OSHA].(2005). Combustible Dust in Industry: Preventing and Mitigating the Effects of Fire and Explosion. Retrieved from https://www.osha.gov/dts/shib/shib073105.html

Occupational Safety \& Health Administration [OSHA].(2005). Chemical Sampling Information Nickel, Metal and Insoluble Compounds. Combustible Dust in Industry: Preventing and Mitigating the Effects of Fire and Explosion Retrieved from https://www.osha.gov/dts/chemicalsampling/data/CH_256200.html

Sarofim, A.F.. Lighty, J.S. (2002). Fine Particles: Health Effects, Characterization, Mechanisms of Formation, and Modeling . Fuel Chemistry Division Preprints, 47(2), 618. Retrieved March 06, 2017, from https://web.anl.gov/PCS/acsfuel/preprint\%20archive/Files/47_2_Boston_1002_0248.pdf.

Staff, ACME. (2015, August 12). Pros and Cons of Additive Manufacturing. Retrieved March 3, 2017, from http://compositesmanufacturingmagazine.com/2014/10/pros-cons-additivemanufacturing/

Stanislav Lagutkin, Lydia Achelis, Sheikhali Sheikhaliev, Volker Uhlenwinkel, Vikas Srivastava, Atomization process for metal powder, Materials Science and Engineering: A, Volume 383, Issue 1, 10 October 2004, Pages 1-6, ISSN 0921-5093, http://dx.doi.org/10.1016/j.msea.2004.02.059. 


\section{Appendix A: Sampling Data: Full Listing}

\begin{tabular}{|c|c|c|c|c|c|c|}
\hline $\begin{array}{l}\text { Sample } \\
\text { Number }\end{array}$ & Analyte & Result & OEL & Units & $\begin{array}{l}\text { \%OEL } \\
\text { PRE-TWA }\end{array}$ & $\%$ OEL \\
\hline 1 & Hex. Chrome & 0.027 & 0.25 & $\mathrm{ug} / \mathrm{m}^{3}$ & $10.8 \%$ & $8.26 \%$ \\
\hline 1 & Total Dust & 0.0203 & 10 & $\mathrm{mg} / \mathrm{m}^{3}$ & $0.20 \%$ & $0.16 \%$ \\
\hline 2 & Nickel & 0.0016 & 0.1 & $\mathrm{mg} / \mathrm{m}^{3}$ & $1.60 \%$ & $1.30 \%$ \\
\hline 2 & Total Dust & 0.025 & 10 & $\mathrm{mg} / \mathrm{m}^{3}$ & $0.25 \%$ & $0.20 \%$ \\
\hline 3 & Total dust & 0.47 & 10 & $\mathrm{mg} / \mathrm{m}^{3}$ & $4.70 \%$ & $1.08 \%$ \\
\hline 4 & Hex. Chrome & 0.16 & 0.25 & $\mathrm{ug} / \mathrm{m}^{3}$ & $64.0 \%$ & $8.93 \%$ \\
\hline 4 & Dust, total & 0.22 & 10 & $\mathrm{mg} / \mathrm{m}^{3}$ & $2.20 \%$ & $0.31 \%$ \\
\hline 5 & Dust, total & 0.62 & 10 & $\mathrm{mg} / \mathrm{m}^{3}$ & $6.20 \%$ & $0.31 \%$ \\
\hline 5 & Nickel & 0.095 & 0.1 & $\mathrm{mg} / \mathrm{m}^{3}$ & $95.0 \%$ & $4.75 \%$ \\
\hline 6 & Hex. Chrome & 0.053 & 0.25 & $\mathrm{ug} / \mathrm{m}^{3}$ & $21.2 \%$ & $10.1 \%$ \\
\hline 6 & Dust, total & 0.04 & 10 & $\mathrm{mg} / \mathrm{m}^{3}$ & $0.40 \%$ & $0.19 \%$ \\
\hline 7 & Hex. Chrome & 0.085 & 0.25 & $\mathrm{ug} / \mathrm{m}^{3}$ & $34.0 \%$ & $7.93 \%$ \\
\hline 7 & Dust, total & 0.21 & 10 & $\mathrm{mg} / \mathrm{m}^{3}$ & $2.10 \%$ & $0.49 \%$ \\
\hline 8 & Chrome metal & 0.038 & 0.5 & $\mathrm{mg} / \mathrm{m}^{3}$ & $7.60 \%$ & $2.85 \%$ \\
\hline 8 & Dust, total & 0.32 & 10 & $\mathrm{mg} / \mathrm{m}^{3}$ & $3.20 \%$ & $1.20 \%$ \\
\hline 8 & Nickel & 0.1 & 0.1 & $\mathrm{mg} / \mathrm{m}^{3}$ & $100 \%$ & $37.5 \%$ \\
\hline 9 & Chrome metal & 0.044 & 0.5 & $\mathrm{mg} / \mathrm{m}^{3}$ & $8.80 \%$ & $3.30 \%$ \\
\hline 9 & Dust, total & 0.19 & 10 & $\mathrm{mg} / \mathrm{m}^{3}$ & $1.90 \%$ & $0.71 \%$ \\
\hline 9 & Nickel & 0.12 & 0.1 & $\mathrm{mg} / \mathrm{m}^{3}$ & $120 \%$ & $45.0 \%$ \\
\hline 10 & Dust, total & 0.18 & 10 & $\mathrm{mg} / \mathrm{m}^{3}$ & $1.80 \%$ & $0.41 \%$ \\
\hline 10 & Nickel & 0.038 & 0.1 & $\mathrm{mg} / \mathrm{m}^{3}$ & $38.0 \%$ & $8.55 \%$ \\
\hline 11 & Hex. Chrome & 0.0033 & 0.5 & $\mathrm{mg} / \mathrm{m}^{3}$ & $0.66 \%$ & $0.17 \%$ \\
\hline 11 & Dust, total & 0.053 & 10 & $\mathrm{mg} / \mathrm{m}^{3}$ & $0.53 \%$ & $0.14 \%$ \\
\hline 11 & Nickel & 0.0033 & 0.1 & $\mathrm{mg} / \mathrm{m}^{3}$ & $3.30 \%$ & $0.87 \%$ \\
\hline 12 & Hex. Chrome & 0.049 & 0.25 & $\mathrm{ug} / \mathrm{m}^{3}$ & $19.6 \%$ & $6.74 \%$ \\
\hline 12 & Dust, total & 1.3 & 10 & $\mathrm{mg} / \mathrm{m}^{3}$ & $13.0 \%$ & $4.47 \%$ \\
\hline 13 & Hex. Chrome & 0.047 & 0.25 & $\mathrm{ug} / \mathrm{m}^{3}$ & $18.8 \%$ & $6.70 \%$ \\
\hline 13 & Dust, total & 1 & 10 & $\mathrm{mg} / \mathrm{m}^{3}$ & $10.0 \%$ & $3.56 \%$ \\
\hline 14 & Chrome(III) & 0.11 & 0.5 & $\mathrm{mg} / \mathrm{m}^{3}$ & $22.0 \%$ & $4.86 \%$ \\
\hline 14 & Dust, total & 0.99 & 10 & $\mathrm{mg} / \mathrm{m}^{3}$ & $9.90 \%$ & $2.19 \%$ \\
\hline 14 & Nickel & 0.33 & 0.1 & $\mathrm{mg} / \mathrm{m}^{3}$ & $330 \%$ & $72.8 \%$ \\
\hline 15 & Chrome(III) & 2.2 & 0.5 & $\mathrm{mg} / \mathrm{m}^{3}$ & $440 \%$ & $95.3 \%$ \\
\hline 15 & Dust, total & 13 & 10 & $\mathrm{mg} / \mathrm{m}^{3}$ & $130 \%$ & $28.2 \%$ \\
\hline 15 & Nickel & 6.9 & 0.1 & $\mathrm{mg} / \mathrm{m}^{3}$ & $6900 \%$ & $1500 \%$ \\
\hline 16 & Chrome(III) & 0.063 & 0.5 & $\mathrm{mg} / \mathrm{m}^{3}$ & $12.6 \%$ & $1.94 \%$ \\
\hline 16 & Dust, total & 1.3 & 10 & $\mathrm{mg} / \mathrm{m}^{3}$ & $13.0 \%$ & $2.00 \%$ \\
\hline 16 & Nickel & 0.19 & 0.1 & $\mathrm{mg} / \mathrm{m}^{3}$ & $190 \%$ & $29.3 \%$ \\
\hline 17 & Chrome(III) & 0.028 & 0.5 & $\mathrm{mg} / \mathrm{m}^{3}$ & $5.6 \%$ & $0.85 \%$ \\
\hline 17 & Dust, total & 1.2 & 10 & $\mathrm{mg} / \mathrm{m}^{3}$ & $12.0 \%$ & $1.83 \%$ \\
\hline 17 & Nickel & 0.087 & 0.1 & $\mathrm{mg} / \mathrm{m}^{3}$ & $87.0 \%$ & $13.2 \%$ \\
\hline
\end{tabular}




\section{Appendix B: Sampling Data - Employee Name, Time, and Date}

\begin{tabular}{|r|l|l|r|r|}
\hline $\begin{array}{l}\text { Sample } \\
\text { Number }\end{array}$ & Task & $\begin{array}{l}\text { Employee } \\
\text { Name }\end{array}$ & $\begin{array}{l}\text { Time } \\
\text { (minutes) }\end{array}$ & \multicolumn{1}{l|}{ Date } \\
\hline 1 & Binder-Jet AM printer Operation & Bill S. & 367 & $10 / 20 / 2015$ \\
\hline 2 & Binder-Jet AM printer Operation & Adam T. & 390 & $9 / 18 / 2015$ \\
\hline 3 & Laser AM printer operation & Jason B. & 110 & $12 / 2 / 2014$ \\
\hline 4 & Laser AM printer operation & Jason B. & 67 & $6 / 8 / 2015$ \\
\hline 5 & Laser AM printer operation & Jason B. & 24 & $3 / 4 / 2015$ \\
\hline 6 & Sieving Powder Operations & Bill B. & 230 & $8 / 19 / 2015$ \\
\hline 7 & Sieving Powder Operations & Bill B. & 112 & $8 / 20 / 2015$ \\
\hline 8 & Sieving Powder Operations & Joe H. & 180 & $7 / 31 / 2015$ \\
\hline 9 & Sieving Powder Operations & Joe H. & 180 & $7 / 31 / 2015$ \\
\hline 10 & $\begin{array}{l}\text { Sample prep - Homogenizing bottles of } \\
\text { powder }\end{array}$ & Bill B. & 108 & $5 / 29 / 2015$ \\
\hline 11 & Sample prep - Homogenizing bottles of & Jaz C. & 127 & $6 / 10 / 2016$ \\
\hline 12 & Nickel atomizer & Ty M. & 165 & $4 / 15 / 2016$ \\
\hline 13 & Nickel atomizer & Curt C. & 171 & $4 / 15 / 2016$ \\
\hline 14 & Nickel atomizer & Ty M. & 106 & $3 / 8 / 2016$ \\
\hline 15 & Nickel atomizer & $\begin{array}{l}\text { Sasha M. } \\
\text { (Contractor) }\end{array}$ & 104 & $3 / 8 / 2016$ \\
\hline 16 & Nickel atomizer & Curt C. & 74 & $3 / 8 / 2016$ \\
\hline 17 & Nickel atomizer & Jeff S. & 73 & $3 / 8 / 2016$ \\
\hline
\end{tabular}

